\title{
MANCHAS DE VINO OPORTO, LA PUNTA DEL ICEBERG PARA MALFORMACIONES VASCULARES CONGÉNITAS
}

\section{PORTO WINE SPOTS, THE POINT OF ICEBERG FOR CONGENITAL VASCULAR MALFORMACIONS}

\author{
Juan Carlos Roque Quezada', Johnny de la Cruz¹, Joseph Alburqueque-Melgarejo, \\ Carolina Carrillo Saldaña ${ }^{1}$, Gabriel Aldea Córdova²
}

Estimados editores, a propósito de la publicación "Factores asociados a malformaciones congénitas" por Ayala FD et al, en el Volumen 8, Numero 4 del 2019; quisiéramos acotar que hubiera sido interesante reportar también las malformaciones congénitas de la piel, muy frecuentemente vistas en nuestro entorno, pero muy poco reportadas. Entre ellas, la que consideramos de particular importancia reportar es la mancha de vino oporto (PWS), también conocida como nevus flammeus. Esta presenta una incidencia considerable del $0.3 \%$ a $0.5 \%$ de la población neonatal, representando la malformación vascular congénita más frecuente en dicha etapa ${ }^{1}$.

Resulta de la ectasia a nivel capilar y venular del tejido dérmico, teniendo como características clínicas ser una mancha de coloración rojo-violácea, vitropresión positiva que respeta la línea media. De todas las ubicaciones posibles, la región hemifacial posee la mayor connotación clínica, ya que puede estar asociada a complicaciones oculares y leptomeníngeas, siendo más prevalente en las lesiones de presentación ipsilateral ${ }^{2,3}$.

Su importancia al identificarla, recae en que un gran porcentaje de estas pueden aparecer aisladamente, sin embargo, un $8 \%$ puede estar asociadas al síndrome de Sturge Weber (SWS), una facomatosis, que cursa clásicamente con PWS hemifacial, glaucoma y/o malformaciones leptomeningeas. Es necesario identificar a todo niño nacido con PWS y realizarle el descarte de este síndrome ya que su pronóstico, si bien depende del compromiso clínico, requiere, a diferencia de la PWS aislada, de un seguimiento a largo plazo por las especialidades de oftalmología y neurología, para su manejo y control ${ }^{3-5}$.

Clínicamente al identificar una PWS es importante delimitar bien su ubicación. Aquellas lesiones que comprometen el área sensitiva de la primera rama del nervio trigémino tienen una fuerte asociación al SWS. Su prevalencia en una lesión que compromete parcialmente esta rama sensitiva es del $26 \%$ y puede aumentar a un $78 \%$ cuando la compromete por completo. Por otro lado, el compromiso aislado de la región palpebral también se ha asociado una elevada asociación de patologías oculares por SWS ${ }^{3-6}$.

Por lo expuesto previamente, con esta carta, buscamos resaltar la importancia de identificar, diagnosticar correctamente y dar seguimiento a las PWS en los servicios de neonatología. Por un lado, para beneficiar al paciente haciendo las referencias pertinentes a los servicios de oftalmología y neurología y descartar cualquier compromiso neuro-ocular en los niños con esta lesión; y por otro, para incentivarlos a realizar investigaciones en este tipo de lesiones muy poco estudiados en nuestro medio pero de gran impacto clínico.

Financiamiento: Autofinanciado.

Conflicto de interés: Los autores declaran no tener algún conflicto de intereses.

\footnotetext{
Instituto de Investigación en Ciencias Biomédicas (INICIB) - Universidad Ricardo Palma

2 Universidad Privada San Martin de Porres. Escuela de Medicina.

Citar como: Roque JC, De La Cruz J, Alburqueque-Melgarejo J, Carrillo C, AldeaG. Manchas de vino oporto, la punta del iceberg para malformacones vasculares congénitas. Rev Peru Investig Matern Perinat 2020; 9(1):9-10

DOI https://doi.org/10.33421/inmp.2020178
}

Recibido: 15-02-20 Aprobado: 12-03-20 


\section{REFERENCIAS BIBLIOGRÁFICAS}

1. Ayala-Peralta FD, Guevara-Ríos E, Carranza-Asmat C, Luna-Figueroa A, Racchumí-Vela A, Mejico-Caja M, Morales-Alvarado S, ValdiviesoOliva V, Reyes-Serrano B, Barbaggelata-Huaraca A, Moreno-Reyes KF. Factores asociados a malformaciones congénitas. Rev Peru Investig Matern Perinat. 2019; 8(4):41-55. https://doi.org/10.33421/ inmp.2019171

2. Thomas-Sohl KA, Vaslow DF, Maria BL. Sturge-Weber syndrome: A review. Pediatric Neurology. 2004;30(5), 303-310. doi:10.1016/j. pediatrneurol.2003.12.015

3. Piram M, Lorette G, Sirinelli D, Herbreteau D, Giraudeau B, Maruani A. Sturge-Weber Syndrome in Patients with Facial Port-Wine Stain. Pediatric Dermatology. 2011;29(1), 32-37.doi:10.1111/j.15251470.2011.01485.x

4. Parsa CF. Focal venous hypertension as a pathophysiologic mechanism for tissue hypertrophy, port-wine stains, the Sturge-
Weber syndrome, and related disorders: proof of concept with novel hypothesis for underlying etiological cause (an American Ophthalmological Society thesis). Trans Am Ophthalmol Soc. 2013 ;111:180-215. PMID: 24385674

5. Comi AM. Topical Review: Pathophysiology of Sturge-Weber Syndrome. Journal of Child Neurology. 2003; 18(8), 509-516.doi:10.1 177/08830738030180080701

6. Piram M, Lorette G, Sirinelli D, Herbreteau D, Giraudeau B, Maruani A. Sturge-Weber Syndrome in Patients with Facial Port-Wine Stain. Pediatric Dermatology. 2011; 29(1), 32-37.doi:10.1111/j.15251470.2011.01485.x.

\section{Correspondencia:}

Juan Carlos Roque Quezada

Direccción: Av. Sucre 623 Dpto. 703 Pueblo Libre

Correo: juankmed26@gmail.com

Teléfono: 945558094 